\title{
Ecological Risk Assessment of HuBaoE Area in Inner Mongolia based on Ecological Footprint Analyses
}

\author{
Jianghong Zhen
}

College of Geography Science, Inner Mongolia Normal University, Huhhot, 010022, China

\author{
基于生态足迹的呼包鄂地区生态风险评价研究 \\ 甄江红 \\ 内蒙古师范大学地理科学学院, 呼和浩特 010022 , 内蒙古
}

\begin{abstract}
Based on the theory, method and model of ecological footprint, this paper measured and analyzed the ecological footprint, ecological carrying capacity, ecological deficit, ecological pressure index and ecological risk degree in Huhhot, Baotou and Erdos from 1990 to 2010. The results show: (1) The per capita ecological footprint has sustained growth in $\mathrm{HuBaoE}$ area since 1990, among which the highest ecological footprint is Erdos, while Baotou takes second place and Hohhot is the minimum. (2) The per capita ecological carrying capacity in Hohhot has continued to decline during 21 years, while that in Baotou and Erdos has gradually risen; the ecological carrying capacity of Erdos is the highest, while that of Hohhot is second, and that of Baotou is the lowest. (3) Hohhot has been ecological surplus during the study period, but its value decreased gradually; Baotou and Erdos transformed to ecologica deficit from ecological surplus in 2004 and 2009 respectively, which shows that they are in ecologically unsustainable stage. (4) The ecological pressure index continued to rise in $\mathrm{HuBaoE}$ area in recent years, the ecological risk degree gradually increased. At present, Hohhot is in intermediate state of ecological risk, while Baotou and Erdos has been in the advanced state of ecological risk.
\end{abstract}

Keywords: ecological footprint; ecological carrying capacity; ecological deficit; ecological pressure index; ecological risk; $\mathrm{HuBaoE}$ area

摘要

基于生态足迹理论、方法与模型，对 1990 2010 年 间呼包鄂地区的生态足迹、生态承载力、生态赤字、 生态压力指数及其生态风险程度进行了测度与分析。 结果表明: (1)1990 年以来呼包鄂地区人均生态足迹持 续增长, 鄂尔多斯市生态足迹最高, 包头市次之, 呼 和浩特市最低。(2) 21 年间呼和浩特市人均生态承载力 不断下降, 包头市与鄂尔多斯市人均生态承载力则逐 步上升；鄂尔多斯市的生态承载力最高，呼和浩特市
次之，包头市最低。(3)研究期内呼和浩特市虽为生态 盈余, 但其数值不断降低; 包头市与鄂尔多斯市则分 别于 2004 年和 2009 年由生态盈余转化为生态赤字, 表明其已处于生态不可持续阶段。(4)近年来呼包鄂地 区生态压力指数持续攀升, 生态风险逐步加大。目前, 呼和浩特市处于生态风险中级状态, 包头市与鄂尔多 斯市已处于生态风险高等级状态。

关键词: 生态足迹; 生态承载力; 生态赤字; 生态压 力指数; 生态风险; 呼包鄂地区

\section{1. 引言}

近年来, 随着生态环境恶化、生态赤字膨胀、自 然灾害加剧[1], 区域生态安全问题日益突出, 生态风 险研究成为学术界关注的焦点[2]。国外生态风险评价 研究始于 20 世纪 80 年代, 美国、英国、澳大利亚、 加拿大、荷兰、南非、欧盟等国家和地区相继提出了 生态风险评价指南及其研究框架 [3,4]。目前, 国际生 态风险评价研究已涉及污染生态风险、生态事件生态 风险、区域生态风险、自然灾害生态风险、人类开发 活动生态风险等多个领域, 风险源由起初的单一化学 污染物扩展至物理干扰、自然灾害及人类活动等多风 险源, 评价尺度从种群、群落、生态系统扩展至区域、 流域和景观水平，风险受体也从单一受体发展到多受 体, 评价方法由传统的污染物扩散模型、统计模型转 变为景观结构模型, 研究框架亦由美国模式衍生出欧 盟模式与笁选模式。

我国生态风险评价研究始于 20 世纪 90 年代中期, 学者们在对生态风险评价的概念、过程、指标、模型、 发展趋势进行探讨的基础上，对水环境和自然灾害、 重金属沉积物、农田系统与转基因作物、人体健康、 土地整理与土地利用、生物安全及项目工程等领域生 态风险评价的基础理论和技术方法进行了探讨 $[5,6,7]$, 运用暴露-响应分析法、压力-状态-响应概念 模型、因子权重法[8]、相对风险评价法、生态等级风 险评价法 [9]、等级动态框架等生态模型方法、景观生 
Risk Analysis and Crisis Response in Big Data Era (RAC-16)

态学方法及 RS、GIS 技术, 对湿地、岛屿、绿洲、流 域、湖区、矿区、海岸带、高原农牧区、城乡交错带、 铁路与公路沿线、部分城市的生态风险进行了综合评 价 [10]。但目前我国在生态系统水平及区域尺度的风 险评价方面还缺少统一的评价理论、量化方法、指标 体系、评价导则与技术规范, 生态风险评价结果也未 体现在风险管理的决策中。今后, 在人体健康和全球 环境两个极端尺度之间, 以区域作为评价尺度的生态 风险评价将逐渐兴起并趋于标准化。

生态足迹法是根据人类社会对自然资源的依赖性 来定量测度区域可持续发展状态的理论与方法[11], 因该方法将可持续发展理念上升到定量测度的可操作 层面, 能够反映在一定的社会发展阶段和技术条件下, 社会经济活动与当时生态承载力间的差距, 在生态安 全和可持续发展评价方面得到广泛运用[12]。目前, 有学者运用生态足迹法对陕西[13]、青海[14]、内蒙古 [15]、黄土高原[16]、中亚区域[12]生态安全的时序变 化进行了测度分析, 而基于生态足迹方法针对呼包鄂 地区开展的生态风险评价还鲜见报道。鉴于呼包鄂地 处我国西部大开发地带、工业经济发展迅速而生态环 境脆弱的特殊性, 本研究基于生态足迹理论与方法, 通过构建生态压力指数模型和生态风险等级划分体 系, 对呼包鄂地区的生态风险状况进行时空分析, 以 期为区域生态风险的评价与比较研究提供学术参考。

\section{2. 研究区概况}

呼和浩特、包头与鄂尔多斯市位于内蒙古中西部, 地 处 $106^{\circ} 42^{\prime} \sim 112^{\circ} 10^{\prime} \mathrm{E}, 37^{\circ} 35^{\prime} \sim 42^{\circ} 40^{\prime} \mathrm{N}$ 间, 由其构成 的 “金三角地带” 集中了全区超过半数的经济总量和 六成以上的财政收入，不仅成为内蒙古经济快速增长 的火车头和助推器, 也是我国重要的能源重化工基地、 西部地区发展最快的经济板块和全国最为活跃的经济 区域之一。截至 2010 年底, 呼包鄂三市总面积占自治 区国土总面积的 $11.28 \%$, 人口占 $30.19 \%$, 而国内生 产总值占 $59.80 \%$, 工业增加值占 $56.32 \%$ 。但因其地 处干旱、半干旱地区, 淡水资源短缺、土地荒漠化加 剧、水土流失严重、沙尘暴频发, 生态环境极端脆弱; 长期以来传统的工业化模式和资源导向型的开发战略 导致了资源过度开发与环境污染加剧, 使其经济增长 面临着严峻的环境态势。鉴于呼包鄂是我国北方及京 津冀重要的生态安全保障区, 开展呼包鄂地区生态风 险评价研究, 对合理确定其人口、资源与环境承载能 力, 建设资源节约型和环境友好型社会具有重要意义。

\section{3. 研究方法与数据来源}

生态风险为一种或多种压力形成的不利生态效应的可 能性过程[17], 生态风险评价是预测人类活动对生态 系统结构、过程和功能产生不利影响的可能性, 是发 现、解决生态环境问题的决策基础[9]。因环境问题的 复杂性、区域性及认识上的局限性[18], 目前国际上 对生态风险的评价指标与研究方法尚未达成共识。从
生态学观点出发, 生态系统的负荷承载能力是有限的, 超过负荷则生态平衡遭受破坏 [19], 从而使生态系统 承受压力, 最终导致生态风险的发生。因生态足迹是 一种衡量人类对自然资源利用程度以及自然界为人类 提供生命支持服务功能的方法 [20], 它通过人类需求 的生态足迹与可供给的生态承载力的比较, 来衡量区 域的生态安全及其生态风险状况[21], 能够形象地反 映出人类经济活动对环境的影响程度 [12], 故本研究 选用该方法来衡量呼包鄂地区生态风险的演变过程。

\section{1 生态足迹测算}

生态足迹是指维持一个地区人类生存和吸纳人类 排放废弃物所需的生物生产性土地面积[20]。它通过 生产性土地的全球平均生产力将资源和废物折算为土 地面积, 并通过均衡因子把不同种类的土地转化为标 准土地。根据生态足迹理论, 将研究区的生态生产性 土地分为 6 大类: 耕地、林地、草地、水域、化石燃 料用地和建筑用地。区域总生态足迹及万元 $G D P$ 生态 足迹的计算公式为 [12]:

$$
E F=N \times e f=N \times \sum_{j=1}^{6}\left(r_{j} \times \sum_{i=1}^{n}\left(a_{i}\right)\right)=N \times \sum_{j=1}^{6}\left(r_{j} \times \sum_{i=1}^{n}\left(c_{i} / p_{i}\right)\right)
$$

式中, $E F$ 为区域总生态足迹, $N$ 为人口数, ef 为区域人均生态足迹, $i$ 为所消费的商品与投入的类 型, $\mathrm{r}_{\mathrm{j}}$ 为均衡因子, $\mathrm{a}_{\mathrm{i}}$ 为第 $i$ 种消费项目折算的人均生 态生产性土地面积, $\mathrm{c}_{\mathrm{i}}$ 为第 $i$ 种消费项目的人均消费 量, $\mathrm{p}_{\mathrm{i}}$ 为第 $i$ 种消费项目的全球平均生产力 [12]。其中, $\mathrm{r}_{j}$ 的取值参考 Wackernagel 对世界各国生态足迹估算 的研究报告 [21], 即: 耕地和建筑用地 2.82 , 林地和 化石燃料用地 1.14 , 草地 0.54 , 水域 0.22 ; 各种资源 消费量来源于《内蒙古统计年鉴》(1991 2011)、《呼 和浩特市经济统计年鉴》（1991 2011）、《包头市统 计年鉴》 (1991 2011) 、 《鄂尔多斯市统计年鉴》 (1991 2011) 及相关部门统计数据; $p_{i}$ 采用联合国粮 农组织 2002 年计算的生物资源的世界平均产量。

\section{2 生态承载力测算}

生态承载力是区域范围内所能提供的各类生态生产性 土地总面积 [13], 其测算公式为:

$$
E C=N \times e c=N \times \sum_{j=1}^{6} a_{j} \times r_{j} \times y_{j}
$$

式中, $\mathrm{EC}$ 为区域生态总承载力, $\mathrm{N}$ 为人口数, ec 为人均生态承载力, $a_{j}$ 为人均某类生态生产性土地面 积, $r_{j}$ 为均衡因子, $y_{j}$ 为产量因子。其中, 产量因子采 用 Wackernagel 文献中计算中国生态足迹时的产量因 子取值[21], 即: 耕地与建设用地 1.66, 林地 0.91 , 草地 0.19 , 水域 1.00 , 化石燃料用地 0 。 
Risk Analysis and Crisis Response in Big Data Era (RAC-16)

\section{3 生态赤字 (盈余) 测算}

生态承载力与生态足迹的差值 (ED) 即生态赤字 (盈 余), 它可定量地反映区域可持续发展现状[12], 即:

$$
E D=E C-E F
$$

$\mathrm{ED}$ 为负时, 将出现生态赤字, 表示该地区人均 资源占用量超过了生态承载力, 生态安全受到威胁; $\mathrm{ED}$ 为正则出现生态盈余, 表示人均资源占用量在生 态承载力允许的范围之内 [12], 自然生态资源发展具 有相对可持续性[21]。

\section{4 生态压力指数测算}

生态压力指数 $(T)$ 是指某一国家或地区可更新资源 的人均生态足迹与生态承载力的比值, 该指数越大, 说明区域的生态压力越大, 生态安全性越差[12], 即:

$$
T=E F / E C \text { 或 } t=e f / e c
$$

据相关研究成果, 可依据 $\mathrm{T}$ 值的大小进行区域生 态风险等级划分，以定量揭示区域生态环境的风险程 度和等级差异（表 1) [13]。

\begin{tabular}{|c|c|c|}
\multicolumn{2}{c|}{ 表 1 生态风险评价标准及其等级划分 } \\
\hline 等级 & 生态压力指数 & 生态风险等级 \\
\hline 1 & $<0.4$ & 低 \\
\hline 2 & $0.4-0.6$ & 较低 \\
\hline 3 & $0.6-0.8$ & 中 \\
\hline 4 & $0.8-1.0$ & 较高 \\
\hline 5 & $>1.0$ & 高 \\
\hline
\end{tabular}

\section{4. 结果分析}

据公式 1 4, 计算出呼包鄂及内蒙古地区 1990 2010 年间的人均生态足迹、人均生态承载力、人均生态赤 字 (盈余) 及生态压力指数（图 1 4、表 2)。

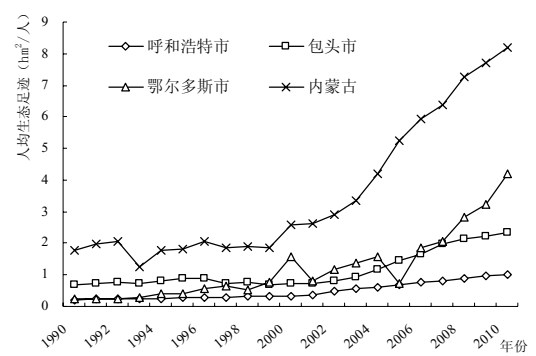

图 1 呼包鄂及内蒙古地区人均生态足迹变化

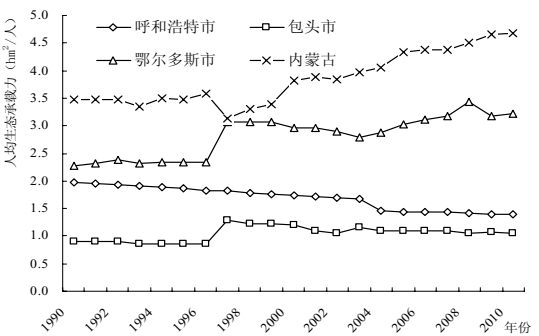

图 2 呼包鄂及内蒙古地区人均生态承载力变化

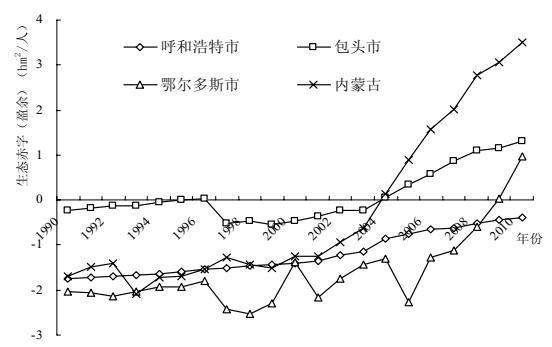

图 3 呼包鄂及内蒙古地区生态赤字 (盈余) 变化

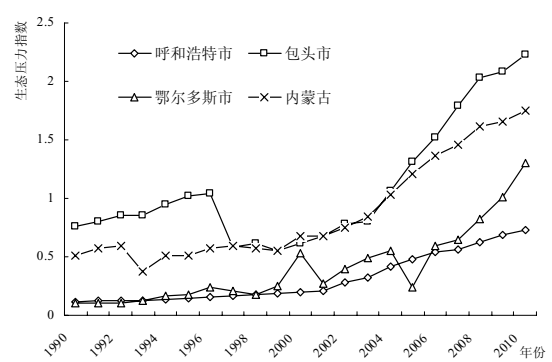

图 4 呼包鄂及内蒙古地区生态压力指数变化

\section{1 呼包鄂地区人均生态足迹稳步增长}

图 1 显示, 1990 2010 年间, 呼包鄂及内蒙古地区人 均生态足迹均有较大增长, 分别由 $0.2197 \mathrm{hm}^{2} /$ 人、 $0.6848 \mathrm{hm}^{2} /$ 人、 $0.2323 \mathrm{hm}^{2} /$ 人、 $1.7878 \mathrm{hm}^{2} /$ 人增加到 $1.0168 \mathrm{hm}^{2} /$ 人、 $2.3569 \mathrm{hm}^{2} /$ 人、 $4.1926 \mathrm{hm}^{2} /$ 人、 $8.1958 \mathrm{hm}^{2} /$ 人, 分别增加了 3.63 倍、2.44 倍、17.05 倍和 3.58 倍, 表明随研究区人均必需的生物生产性面积的增加, 社 会经济以较快的发展速度不断推进。从各类土地生态 足迹所占比重来看, 呼包鄂三市及内蒙古均以化石燃 料用地最高, 其生态足迹比重均值分别达 $43.78 \%$ 、 $66.26 \% 、 53.53 \%$ 和 $46.03 \%$, 表明其生态足迹的增长主 要体现在化石能源用地上。 
Risk Analysis and Crisis Response in Big Data Era (RAC-16)

表 2 1990-2010 年间呼包鄂及内蒙古地区生态压力指数与生态风险等级

\begin{tabular}{|c|c|c|c|c|c|c|c|c|}
\hline \multirow[b]{2}{*}{ 年份 } & \multicolumn{2}{|c|}{ 呼和浩特市 } & \multicolumn{2}{|c|}{ 包头市 } & \multicolumn{2}{|c|}{ 鄂尔多斯市 } & \multicolumn{2}{|c|}{ 内蒙古 } \\
\hline & $\begin{array}{c}\text { 生态压力 } \\
\text { 指数 }\end{array}$ & $\begin{array}{c}\text { 生态风险 } \\
\text { 等级 }\end{array}$ & $\begin{array}{l}\text { 生态压力 } \\
\text { 指数 }\end{array}$ & $\begin{array}{l}\text { 生态风险 } \\
\text { 等级 }\end{array}$ & $\begin{array}{l}\text { 生态压力 } \\
\text { 指数 }\end{array}$ & $\begin{array}{c}\text { 生态风险 } \\
\text { 等级 }\end{array}$ & $\begin{array}{l}\text { 生态压力 } \\
\text { 指数 }\end{array}$ & $\begin{array}{c}\text { 生态风险 } \\
\text { 等级 }\end{array}$ \\
\hline 1990 & 0.1117 & 低 & 0.7582 & 中 & 0.1024 & 低 & 0.5130 & 较低 \\
\hline 1991 & 0.1203 & 低 & 0.8002 & 较高 & 0.1059 & 低 & 0.5706 & 较低 \\
\hline 1992 & 0.1285 & 低 & 0.8494 & 较高 & 0.1057 & 低 & 0.5933 & 较低 \\
\hline 1993 & 0.127 & 低 & 0.8548 & 较高 & 0.1264 & 低 & 0.3734 & 低 \\
\hline 1994 & 0.1318 & 低 & 0.9448 & 较高 & 0.1700 & 低 & 0.5062 & 较低 \\
\hline 1995 & 0.1476 & 低 & 1.0193 & 高 & 0.1744 & 低 & 0.5154 & 较低 \\
\hline 1996 & 0.1595 & 低 & 1.0447 & 高 & 0.2369 & 低 & 0.573 & 较低 \\
\hline 1997 & 0.1661 & 低 & 0.5846 & 较低 & 0.2127 & 低 & 0.5903 & 较低 \\
\hline 1998 & 0.1803 & 低 & 0.6113 & 中 & 0.1753 & 低 & 0.5709 & 较低 \\
\hline 1999 & 0.1873 & 低 & 0.5511 & 较低 & 0.2469 & 低 & 0.5513 & 较低 \\
\hline 2000 & 0.1945 & 低 & 0.6101 & 中 & 0.5331 & 较低 & 0.6725 & 中 \\
\hline 2001 & 0.2074 & 低 & 0.6743 & 中 & 0.2732 & 低 & 0.6759 & 中 \\
\hline 2002 & 0.2837 & 低 & 0.7797 & 中 & 0.3990 & 低 & 0.7537 & 中 \\
\hline 2003 & 0.3266 & 低 & 0.8006 & 较高 & 0.4914 & 较低 & 0.8412 & 较高 \\
\hline 2004 & 0.4152 & 较低 & 1.0606 & 高 & 0.5521 & 较低 & 1.0348 & 高 \\
\hline 2005 & 0.4817 & 较低 & 1.3136 & 高 & 0.2446 & 低 & 1.2075 & 高 \\
\hline 2006 & 0.5455 & 较低 & 1.5245 & 高 & 0.5917 & 较低 & 1.3601 & 高 \\
\hline 2007 & 0.5676 & 较低 & 1.7954 & 高 & 0.6476 & 中 & 1.4568 & 高 \\
\hline 2008 & 0.6267 & 中 & 2.0332 & 高 & 0.8228 & 较高 & 1.6153 & 高 \\
\hline 2009 & 0.6873 & 中 & 2.086 & 高 & 1.0123 & 高 & 1.6552 & 高 \\
\hline 2010 & 0.7294 & 中 & 2.2245 & 高 & 1.3005 & 高 & 1.7489 & 高 \\
\hline
\end{tabular}

21 年间研究区生态足迹的增长速度并不均衡,

表现出阶段性递增的特点（图 1)。1990 2000 年间, 呼包鄂三市及内蒙古人均生态足迹有小幅波动且增 长缓慢; 2000 2010 年间, 其人均生态足迹呈现出近 乎直线型的增长态势。可见, 2000 年以来, 随着国 家西部大开发战略的实施及经济快速增长, 其生态足 迹水平快速提升。究其原因, 与该时期内研究区人口 数量增加、城市化与工业化进程加快、居民生活水平 及消费水平提高导致对自然资源、化石能源及建设用 地的开发强度加大, 对粮食、蔬菜、肉类等生物资源 需求与消费量增大有关。

研究时段内呼包鄂三市的生态足迹水平及其变 化特征具有一定差异, 但均低于内蒙古同期的平均水 平 (图 1)。从多年均值来看, 1990 2000 年间, 包 头市的生态足迹最高, 为 0.7637 ; 鄂尔多斯市次之, 为 0.5377 ; 呼和浩特市最小, 仅 0.2755 。可见, 作为 自治区最大的工业城市, 包头市因矿产资源与化石能 源消耗巨大, 其生态足迹水平位居首位。2000 2010 年间, 鄂尔多斯市的生态足迹最高, 为 1.9438 ; 包头 市次之, 为 1.4720 ; 呼和浩特市最小, 为 0.6798 。究 其原因, 近年来鄂尔多斯市依托于得天独厚的资源优 势, 工业经济超常规发展, 随着资源与能源消耗量剧 增, 人均资源占有量大幅增加, 使其生态足迹水平快

速提升, 但人类经济活动对环境影响的程度亦随之加 大。整个研究时段内, 鄂尔多斯市人均生态足迹水平 最高, 为 1.2246 ; 包头市次之, 为 1.1365 ; 呼和浩特 市最小, 仅 0.4853 。可见, 城市性质及产业结构的差 异决定了生态足迹的不同, 同为工业城市的包头市与 鄂尔多斯市因资源开发与能源需求强度大, 使其生态 足迹维持较高水平。从生态足迹的增长幅度来看, 以 鄂尔多斯市最大, 呼和浩特市次之, 包头市最低, 且 鄂尔多斯市生态足迹增长速度远高于呼和浩特市、包 头市及全区平均水平, 体现出其经济增长势头迅猛, 具有超常规的发展态势和巨大的开发潜力。

4.2 呼包鄂地区人均生态承载力变化具区域差异, 呼 和浩特市持续下降,包头与鄂尔多斯市则呈上升趋势

图 2 表明, 1990 2010 年间呼包鄂三市人均生态承载 力的变化趋势不尽相同。其中, 呼和浩特市人均生态 承载力呈持续下降态势, 由 $1.9675 \mathrm{hm}^{2} /$ 人降至 $1.3941 \mathrm{hm}^{2} /$ 人, 降低了 $29.14 \%$, 表明其生态容量逐渐 减小。分析表明, 呼和浩特市生态承载力的减少主要 是由耕地面积的减少所致, 体现出城市用地的扩张对 耕地资源的侵占，使耕地资源面临的压力持续加大。 而同期内, 包头市、鄂尔多斯市及内蒙古的人均生态 承载力则在波动中不断增加, 分别由 $0.9031 \mathrm{hm}^{2} /$ 人、 
$2.2686 \mathrm{hm}^{2} /$ 人、 $3.4868 \mathrm{hm}^{2}$ /人, 增加到 $1.0595 \mathrm{hm}^{2} /$ 人、 $3.2239 \mathrm{hm}^{2} /$ 人、 $4.6863 \mathrm{hm}^{2} /$ 人, 分别增加了 0.17 倍、 0.42 倍和 0.34 倍, 说明其生态供给量有加大趋势; 其中鄂尔多斯市生态承载力上升幅度高于包头市及 全区平均水平, 这与其耕地与林地资源数量持续增加 密切相关, 表明其土地整治与生态保护初见成效。

研究期内, 鄂尔多斯市人均生态承载力的平均 水平最高, 为 $2.8177 \mathrm{hm}^{2} /$ 人; 呼和浩特市次之, 为 $1.6902 \mathrm{hm}^{2} /$ 人; 包头市最低, 仅 $1.0453 \mathrm{hm}^{2} /$ 人, 表明 其生态供给存在区域差异。但呼包鄂三市的平均生态 承载力均低于内蒙古同期平均水平 $\left(3.8432 \mathrm{hm}^{2} /\right.$ 人), 且呼和浩特与包头市人均生态承载力还低于全球平 均水平 $\left(2 \mathrm{hm}^{2} /\right.$ 人) $[21]$, 表明发展形势较为严峻。

\section{3 呼包鄂地区逐渐由生态盈余向生态赤字转化, 且生态赤字有加剧趋势}

图 3 显示, 研究区生态赤字 (盈余) 变化特征有一定 差异, 但其曲线均具下降趋势。其中, 呼和浩特市在 研究时段内均为生态盈余, 但其数值不断减小, 由 $1.7478 \mathrm{hm}^{2} /$ 人减少到 $0.3773 \mathrm{hm}^{2} /$ 人, 年均减少 $0.065 \mathrm{hm}^{2} /$ 人, 表明其自然生态资源的可持续程度逐 渐降低。同时期内, 包头市生态盈余与生态赤字则交 替出现, 即: 1990 1994 年间为生态盈余, 虽然自然 资源可满足经济增长需求, 但其数值逐年减小; 1995 1996 年间为生态赤字, 生态系统资源供给能力 不足以满足资源消费，但其间差值不大； 1997 2003 年间又为生态盈余, 且数值不断降低; 2004 2010 年 间为生态赤字, 并有加剧趋势, 表明生态基础将会成 为经济增长的制约因素。鄂尔多斯市则逐渐由生态盈 余转化为生态赤字, 即: 1990 2008 年间为生态盈余, 但数值在波动中迅速减少; 2009 2010 年间处于生态 赤字, 且有增大态势, 表明生态系统的供给能力已不 能满足经济系统的需求。内蒙古于 2004 年后出现生 态赤字, 表明生态系统正常提供的生态基础已不能满 足经济活动的生态需求。截至 2010 年, 包头市与鄂 尔多斯市的生态赤字分别达 $1.2974 \mathrm{hm}^{2} /$ 人和 $0.9688 \mathrm{hm}^{2} /$ 人, 虽均低于内蒙古的赤字水平 (3.5095 $\mathrm{hm}^{2} /$ 人) , 但二者已处于生态不可持续阶段。

从生态赤字 (盈余) 的发展过程来看, 包头市于 2004 年率先出现生态赤字, 鄂尔多斯市于 2009 年出 现生态赤字, 体现出城市经济发展历程的差异。作为 内蒙古建设最早的工业城市, 资源开发型的经济特征 使包头市对能源资源需求巨大, 导致其对自然资源的 消耗很快超过了生态承载力, 存在资源过度利用现 象; 鄂尔多斯市的资源开发与经济建设起步较晚, 但 作为自治区乃至全国的能源原材料基地, 以资源依赖
型为特征的重型工业经济使其对矿产资源的消耗量 日益增大, 随着资源开采压力逐步加大, 生态承载力 与生态足迹之间的平衡渐趋失调。呼和浩特市虽未在 研究时段内出现生态赤字, 但其生态盈余快速减少, 若按此趋势发展, 其生态系统资源供给能力将不足以 满足资源消费, 从而使其生态安全受到胁迫。

4.4 呼包鄂地区生态压力指数不断攀升, 生态风险持 续增大, 包头与鄂尔多斯市处于生态风险高等级状态

由图 4 可知, 1990 2010 年间, 呼包鄂与内蒙古 地区生态压力指数均在波动中快速增加, 分别由 $0.1117 、 0.7582 、 0.1024 、 0.5130$ 增加到 $0.7294 、 2.2245$ 、 $1.3005 、 1.7489$, 分别增加了 5.53 倍、 1.93 倍、 11.70 倍和 2.41 倍, 其中鄂尔多斯市的增幅最大, 表明随 经济的快速增长及资源的过度利用, 其生态系统功能 遭到破坏, 不仅使生态系统的资源供给能力大幅降 低, 亦使生态压力迅速增大。

表 2 表明, 1990 2003 年间, 呼和浩特市生态状 况处于低风险等级; 2004 2007 年间, 处入生态风险 较低级状态; 2008 年后进入生态风险中级状态。包 头市生态风险状况则在 1990 2010 年间经历了由中 级一较高级一高级一较低级一中级一较高级一高级 的波动变化, 2004 年以来生态状况处于高风险等级。 鄂尔多斯市生态风险由低级、较低级、中级、较高级 向高级转化, 2009 年后处于高等级生态风险状态。 内蒙古先后处于较低、中、较高级生态风险中, 2004 年后转变为高等级生态风险。可见, 呼包鄂三市及内 蒙古的生态风险持续增加, 除呼和浩特市外, 目前包 头市、鄂尔多斯市及内蒙古已处于生态风险高等级状 态, 其中以包头市的生态压力最大, 生态风险最高。

从平均水平来看, 21 年间以包头市的生态压力 指数均值最高, 为 1.0915 , 高于全区平均水平 (0.8753); 其次为鄂尔多斯市, 为 0.4059 ; 呼和浩 特市最低, 为 0.3108 。可见, 作为自治区最大的工业 城市, 长期以来的资源开发与能源消耗模式已经导致 包头市的生态供给能力严重超载; 而作为全区的政 治、经济、文化中心, 因资源消耗与环境污染相对较 轻, 呼和浩特市的生态压力相对最小。

\section{5. 结论与讨论}

本研究借鉴生态足迹理论与方法, 通过构建生态足 迹、生态承载力、生态赤字、生态压力指数模型以及 生态风险等级划分体系, 对呼包鄂及内蒙古地区的生 态风险状况进行了时空评析, 结果表明:

（1）1990 2010 年间呼包鄂地区人均生态足迹 稳步增长并具阶段性递增特点, 其中以化石燃料用地 
Risk Analysis and Crisis Response in Big Data Era (RAC-16)

足迹的增幅最大。研究期内, 呼包鄂三市的生态足迹 均低于内蒙古同期平均水平, 其中鄂尔多斯市的人均 生态足迹最高, 包头市次之, 呼和浩特市最小, 表明 城市性质及产业结构的差异导致了生态足迹的不同。

(2) 研究时段内呼和浩特市人均生态承载力不 断下降, 体现出城市用地的扩张使耕地资源面临的压 力逐步加剧; 包头市与鄂尔多斯市人均生态承载力则 持续上升, 表明其生态供给量有加大趋势。三城市中 以鄂尔多斯市的平均生态承载力水平最高, 呼和浩特 市次之, 包头市最低, 但均低于内蒙古同期平均水平, 表明其生态供给存在区域差异, 发展形势较为严峻。

（3） 21 年间呼和浩特市虽为生态盈余, 但其数 值持续减小, 表明自然生态资源的可持续程度逐渐减 小; 包头市与鄂尔多斯市分别于 2004 年和 2009 年由 生态盈余转化为生态赤字, 且生态赤字有加剧趋势, 表明其资源利用过度, 目前二者的生态赤字虽均低于 内蒙古平均水平, 但已处于生态不可持续阶段。

(4) 研究期内呼包鄂地区生态压力指数不断攀 升, 生态风险程度持续增加。目前, 呼和浩特市生态 风险处于中级阶段, 包头市与鄂尔多斯市已处于高风 险状态, 且以包头市的生态压力最大, 生态风险最大。

（5）虽然生态足迹方法已得到普遍关注，但它 还存在着研究范围有限、未包含水资源足迹的供给、 因使用国家统一产量因子会使生态承载力的计算出 现偏差、因未考虑技术变化或社会系统适应能力等情 况而简化了自然和社会关系等缺陷[22]。但因其研究 结果能在一定程度上揭示区域生态风险的动态变化, 因而仍具有一定的研究价值。

（6）本文的研究结果可为呼包鄂地区生态风险 管理提供依据, 以便选用有效的控制技术和适当的 管理措施并付诸实施, 从而降低或消除生态风险程 度, 保障生态系统的健康与安全。

\section{Acknowledgements}

This study was supported by the National Science Foundation of Inner Mongolia(No. 2016MS0410) .

\section{致谢}

本研究得到了内蒙古自然科学基金项目 (2016MS0410)的资助。

\section{6.参考文献}

[1] 陈星, 周成虎.生态安全: 国内外研究综述.地理 科学进展，2005，24（6）：8-20.

[2] 张百平, 姚永慧, 朱运海, 等.区域生态安全研究 的科学基础与初步框架. 地理科学进展, 2005, 24 (6) : $1-6$.
[3] 孙琦. 大型露天煤矿土地损毁生态风险评价及空 间防范措施一以平朔安太堡露天矿为例. 中 国地质大学硕士学位论文, 2014 .

[4] 苏特尔 (美) 著.尹大强, 林志芬, 刘淑慧, 等译. 生态风险评价（第二版）。北京：高等教育出 版社, 2011, 6.

[5] 潘雅婧, 王仰麟, 彭建, 等.矿区生态风险评价研 究述评.生态学报，2012，32（20）：6566-6574.

[6] Rongfang Li.An Operational drought risk management framework based on stream-flow intelligent internet control. Journal of Risk Analysis and Crisis Response, 2013, 3 (1) : 34-43.

[7] Qinghua Gong.Research on characteristics and formation mechanism of landslide disaster in Red Soil Hilly Region of South China.Journal of Risk Analysis and Crisis Response. 2013, 3 (2) : 110-114.

[8] 曾勇. 区域生态风险评价一以呼和浩特市区为 例.生态学报，2010,30（3）：668-673.

[9] 吴莉, 侯西勇, 邸向红.山东省沿海区域景观生态 风险评价.生态学杂志, 2014, 33 (1)：214-220

[10] 张小飞, 王仰麟, 李正国, 等.基于氮排放估算 的区域生态风险评价一以中国台湾地区为例 .生态学报，2016，36（4）：893-903.

[11] 冯伟, 周泽龙, 陈维, 等.生态足迹研究方法综 述.河北农业科学，2008，12（6）：3-4.

[12] 吉力力.阿不都外力, 木巴热克.阿尤普.基于生态 足迹的中亚区域生态安全评价.地理研究, 2008, 27 (6) : 1308-1320.

[13] 任志远, 黄青, 李晶.陕西省生态安全及空间差 异定量分析.地理学报，2005，60（4）：597-606.

[14] 韦良焕, 赵先贵, 高利峰.基于生态足迹的青海 省生态安全初步研究.水土保持通报，2007，27 (27)：155-158.

[15] 刘海涛.基于能值生态足迹模型的内蒙古自治区 生态承载力与生态安全研究.西南大学硕士学位 论文, 2011 .

[16] 任志远.陕北黄土高原生态安全动态变化定量分 析. 干早区地理，2005，28（5）：642-646.

[17] 殷浩文. 生态风险评价.上海: 华东理工大学 出版社, 2001.

[18] 李佩武, 李贵才, 张金花, 等.城市生态安全的 多种评价模型及应用.地理研究, 2009, 28 (2): 293-302.

[19] 谢花林, 李波.城市生态安全评价指标体系与评 价方法研究. 北京师范大学学报 (自然科学 版)，2004，40（5）：705-710.

[20] 王书华, 毛汉英, 王忠静. 生态足迹研究的国内 外近期进展. 自然资源学报, 2002, 17（6）: 776-782.

[21] 张伟新, 范晓秋, 姜翠玲, 等.生态评价方法与 区域生态足迹评价一以无锡市为例. 南京财经 大学学报, 2005, 132（2）: 24-28.

[22] 黎瑞波, 蒋菊生.生态足迹分析模型及其研究现 状. 华南热带农业大学学报, 2004, 10(2): 12-15. 